\title{
Survey on Student-Centered Learning Assessment and Feedback Practices - Research Brief
}

\author{
Ofer Chen \\ of er. chen@nyu.edu
}

\author{
Yoav Bergner \\ yoav . bergner@nyu . edu
}

December 2021

\begin{abstract}
The challenge of assessing student progress and using information gained through assessment to improve teaching and learning is formidable. It can be argued that in student-centered learning (SCL) environments that challenge is even greater than in traditional frontal instruction classrooms. To better understand the assessment and feedback-giving practices of teachers in SCL classrooms, we invited teachers from across the United States to share with us their classroom practices relating to assessment and feedback-giving, the types of feedback they give to students, and their beliefs about the benefits and costs associated with feedback-giving. The goal of this report is to share back our preliminary findings with the participating teachers.
\end{abstract}

\section{Background}

The SCL assessment and feedback-giving practices survey was distributed from May to December 2021 in coordination with large SCL teacher networks such as MakerEd, Fablearn, and STEMteachersNYC. The initial survey distribution was followed by a request from respondents to share the survey with peer teachers who also have interest in the topics of assessment and feedback. This spread from teachers to other teachers in their own networks is often referred to as "snowball sampling". The process resulted in 180 valid responses from 15 states in the U.S. In this research brief, we share some initial survey results, sidestepping the typically long publication cycle of academia. We do this to relay information while it is fresh and relevant to the contributing teachers and to others grappling with the challenge of assessing and supporting learning in SCL classrooms. It should be noted that future publications may differ in focus and analytic methods from this brief.

The survey included four sections:

- Demographics - Designed to get a high-level view of who responded to the survey and to enable group comparisons.

- Practices - Designed to collect information about the assessment and feedback practices teachers employ in SCL classrooms, including assessment types, development and revision processes, feedback communication to students, etc.

- Teacher Feedback Orientation Spectrum (TFOS) - a new instrument designed to better understand the types of feedback teachers give their students.

- Feedback Benefits and Costs (FB\&C) - a new instrument designed to learn about the perceived benefits and costs teachers associate with giving feedback to students.

Two new instruments, described above, were developed by adapting portions of prior ones: the Teacher Conception of Feedback instrument (TCoF) (Brown, Harris, \& Harnett, 2012) and 
the Teacher Assessment for Learning Questionnaire (TAFL-Q) (Pat-El, Tillema, Segers, \& Vedder, 2013). Analysis of the new questionnaires for psychometric quality is still pending. The results reported here with respect to these sections should therefore be taken with a grain of salt.

\section{Who Answered The Survey?}

The survey criteria required that all respondents are a) teachers in grades 1-12, b) actively teaching or have taught in the past 3 years, c) in a U.S. classroom, and d) primarily employ a pedagogy associated with student-centered learning.

\section{Teacher Geography, Gender, and Age}

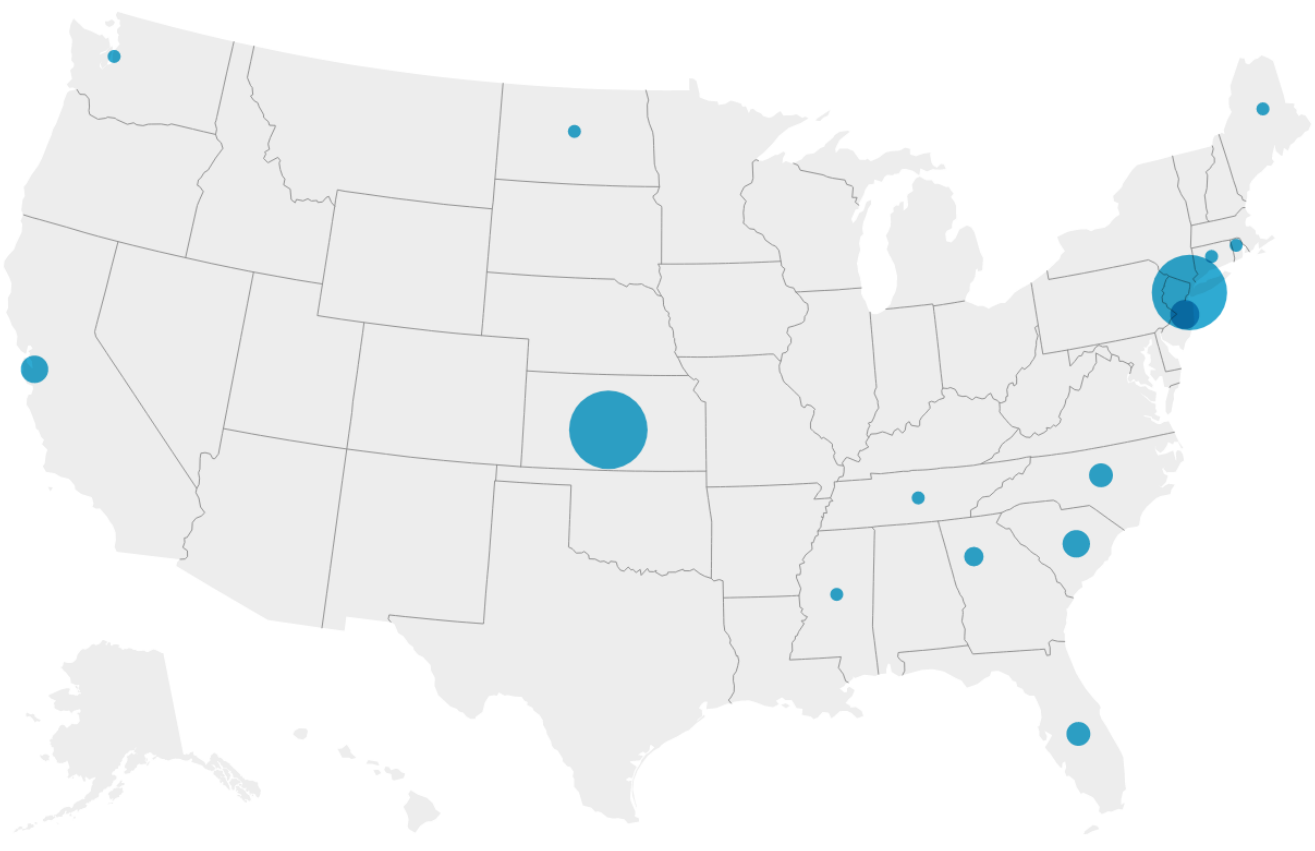

We collected 181 responses from teachers teaching in 15 U.S. states. A large portion of the responses came from Kansas (72 responses, 40\%) and New York (65 responses, $36.1 \%$ ) due to the snowball sampling method, followed by New Jersey (8 responses, 4.5\%), California and South Caroline (7 responses, $3.9 \%$ each), Florida and North Carolina (5 responses, $2.7 \%$ each), Georgia (3 responses, $1.7 \%$ ), and one response was received from each of the following states: Connecticut, Figure 1: Respondent Gender Maine, Mississippi, North Dakota, Rhode Island, Tennessee, and Washington state.

Teachers in this sample predominantly identified as female (152 responses, 84.4\%), with 26 identifying as male $(14.4 \%)$, one as non-binary $(0.6 \%)$ and one preferred not to answer $(0.6 \%)$. The mean age of respondents was $42.8(\mathrm{SD}=10.3$, median $=43)$. 
Figure 2: Respondent Age

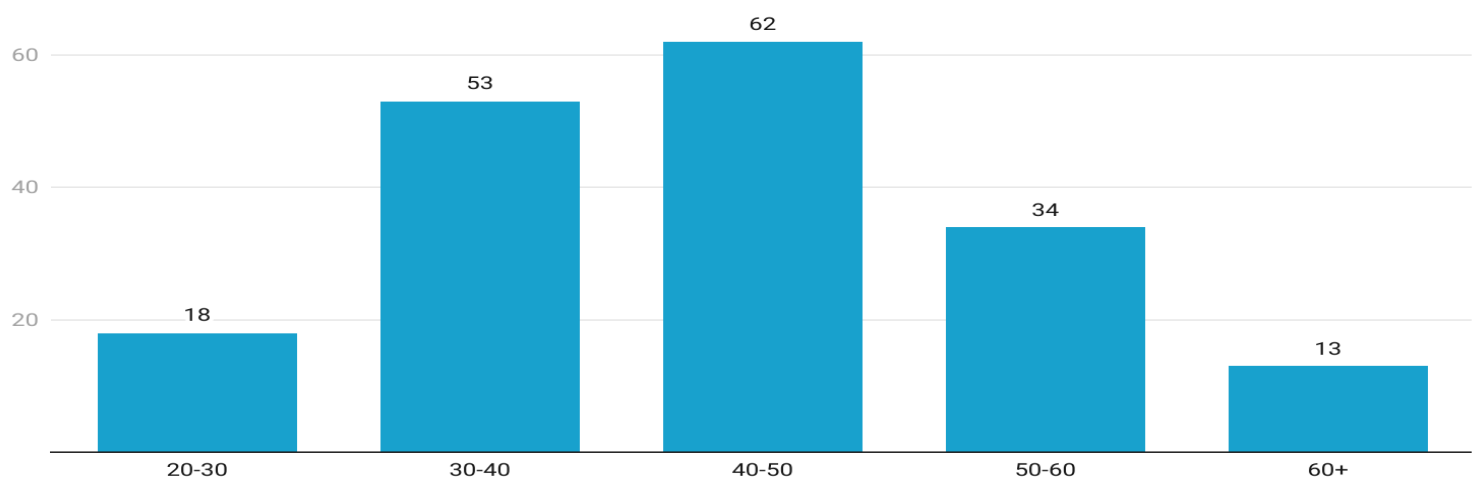

\section{Teacher Education, Tenure, and Assessment Training}

The teachers in this sample are highly educated, experienced, and tend to have had formal assessment training. Moreover, the data suggests that respondents are well-versed in both the theory and the application of classroom assessments.

Figure 3: Highest Degree Obtained

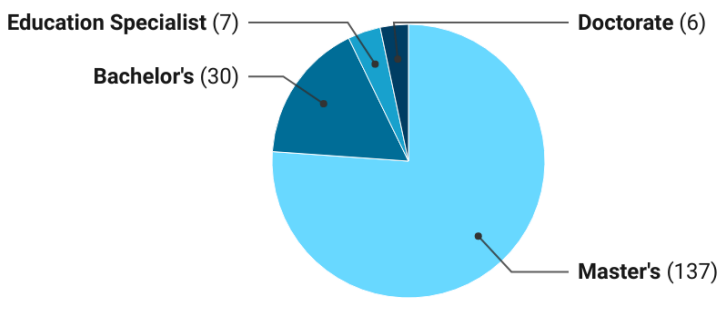

The highest degree for the vast majority of respondents is a Master's (137 responses, $76.1 \%)$. The breakdown for the remainder were: Bachelor's (30, 16.7\%), Education Specialist degree $(7,3.9 \%)$, and Doctorate $(6$, $3.3 \%$ ). Teaching experience was normally distributed with a mean of 14.25 years of experience $(\mathrm{SD}=8.4$, median=14). Finally, 144 of the $180(80 \%)$ respondents reported to have had formal training through an academic course or professional development specifically focused on the topics of assessment or educational measurement.

Figure 4: School Type in public school, including traditional public schools (144 responses, 80\%), Charter schools (10 responses, 5.6\%), and Magnet schools (3 responses, $1.7 \%)$. Only 23 responses $(12.8 \%)$ came from private school teachers. Furthermore, 155 of the teachers in the survey reported that their class is a mandatory part of their students' curriculum $(86.1 \%)$ versus 25 who reported their class being an elective (13.9\%). In addition, the mean number of students in each classroom was 22.1 $(\mathrm{SD}=10.6$, median $=22)$. Teachers in this survey teach across all grade levels, most teaching in more than one grade, with a small underrepresentation of teachers in grades $5-8$. 
Figure 5: Grade Level Distribution

\begin{tabular}{lllllllllllll}
$\begin{array}{l}\text { Grade } \\
\text { Level }\end{array}$ & $\mathbf{1}$ & $\mathbf{2}$ & $\mathbf{3}$ & $\mathbf{4}$ & $\mathbf{5}$ & $\mathbf{6}$ & $\mathbf{7}$ & $\mathbf{8}$ & $\mathbf{9}$ & $\mathbf{1 0}$ & $\mathbf{1 1}$ & $\mathbf{1 2}$ \\
\hline & 41 & 37 & 38 & 38 & 36 & 26 & 31 & 31 & 43 & 42 & 45 & 49
\end{tabular}

It is important to point out that some of the school and classroom characteristics can be a explained as a result of using snowball sampling to collect many of the responses included in this analysis. However, we still find these figures to be somewhat surprising.

\section{Pedagogical Approach}

Student-centered learning covers a wide range of instructional methods and learning experiences designed to support the specific needs and ambitions of individual students. Diversity of methods was a purposeful goal in our sampling. We sought out to identify both commonalities and differences that may exist between teachers who predominantly use one approach or another. (Sub-group comparisons are not reported in this brief). Even though the snowball method of sampling could have resulted in more uniform approaches, responding teachers reported a wide variety of instructional methods in their classrooms.

The largest group (51 responses, $28.3 \%$ ) used inquirybased learning in their classroom, followed by direct instruction $(42,23.3 \%)$, project-based learning $(38,21.1 \%)$, problembased learning $(10,5.6 \%)$, maker education $(10,5.6 \%)$, and experiential learning $(5,2.8 \%)$. Of the $24(13.3 \%)$ respondents who selected the 'other' option, all Figure 6: Teaching Method but one described blending two or more of the instructional methods from the list. One teacher indicated the use of modelling instruction.

\section{SCL Teacher Assessment Practices}

In addition to standard measures of student achievement and knowledge, teachers in SCL classrooms care about a variety of skills and attitudes such as collaboration and communication skills, emotional resilience, design thinking, and problem solving. These skills and attitudes are sometimes referred to as "soft skills" and are considered to be hard-to-measure by assessment experts.

In this study, we were interested in better understanding the ways in which SCL teachers approach assessment, the types of assessments they employ, how those are developed and revised, and what, if any, instruments are used in grading them. 


\section{What Assessments Are Used?}

The survey results indicate that SCL teachers use many different assessments of knowledge, skills, and attitudes to elicit evidence of learning and growth. On average, teachers reported using 11 different assessment types (from a selection of 15) at least once each term. While some assessments are only used once or twice per term, many are used at least every two weeks.

Figure 7: Assessment Usage Frequency. (Frequent use here indicates 3+ times per term.

Occasional use indicates 1-3 times per term.)

\begin{tabular}{|c|c|c|c|}
\hline Assessment Type & Frequent & Occasional & Never \\
\hline Classroom discussions & 150 & 20 & 10 \\
\hline $\begin{array}{l}\text { Worksheets, problem sets, or } \\
\text { tutorials }\end{array}$ & 116 & 40 & 24 \\
\hline Quizzes & 76 & 67 & 37 \\
\hline Student reflections & 72 & 70 & 38 \\
\hline $\begin{array}{l}\text { Authentic/performance } \\
\text { assessment }\end{array}$ & 66 & 87 & 27 \\
\hline Self-review & 57 & 85 & 38 \\
\hline Peer-reviews & 28 & 92 & 60 \\
\hline Group projects & 41 & 103 & 36 \\
\hline Individual projects & 40 & 113 & 27 \\
\hline Student journals & 42 & 55 & 83 \\
\hline Student presentations & 29 & 122 & 29 \\
\hline Student portfolios & 28 & 67 & 85 \\
\hline Student reports or essays & 26 & 97 & 57 \\
\hline Major tests - Closed ended & 25 & 94 & 61 \\
\hline Major tests - Open ended & 13 & 86 & 81 \\
\hline
\end{tabular}

The responses demonstrate that no assessment type is "off the table". All types are used at least occasionally by more than $50 \%$ of teacher respondents. The least popular assessments are student journals, student portfolios, and major tests. Major tests are often viewed (and sometimes criticized) as the central form of assessment used in schools. These results may point to SCL teachers' move away from traditional assessments to embrace a wide range of methods to elicit evidence of learning from students.

The assessment most commonly used by respondents to this survey are classroom discussions. 
While classroom discussions provide invaluable information to teachers on where students stand in terms of their knowledge, skills, and attitudes (KSAs), it is challenging to collect and organize that information. Further research may be needed to better understand the strategies teachers use to make sense of the real-time, dynamic, context-dependent, and unstructured evidence that arises in discussions.

Other commonly used categories of assessment include 'worksheets, problem sets, or tutorials' and quizzes. These provide a more structured way to check in with students on a regular basis. These are followed by student reflections and authentic/performance assessments. These latter forms of assessment are often touted as eliciting more relevant evidence of learning than traditional tests. Employing these assessments in SCL classrooms is commonly viewed as desirable since they provide more contextual, real-world evidence of learning and in the case of reflections, a glimpse into students' emotions and thinking processes.

\section{Assessment Development and Revision}

While teachers in this sample report to using a broad assortment of assessments in their classrooms, they tend to develop those assessments on their own or with their immediate peers and revise them on a regular basis. When asked where they get the assessments they use in class, 71 respondents (39.4\%) indicated that they typically develop them on their own and $41(22.8 \%)$ reported developing assessments collaboratively with their colleagues. 7 (3.9\%) use or adapt assessments developed by teachers from their school and $19(10.6 \%)$ use or adapt assessments developed by teachers from other schools. Only $37(20.6 \%)$ respondents use assessments provided by published online or print resources such as textbooks or use state- or district-provided standardized materials. Five chose the 'other' option and mainly reported a mixture of the aforementioned methods.

In addition, a majority of the respondents regularly revise assessments assigned to students, both before and during an academic term (116 responses, $64.4 \%$ ) and a large portion review the assessments for a given class before the term begins and make revisions when needed ( 55 responses, $30.6 \%)$. Only $9(5 \%)$ respondents say they assign pretty much the same assessments every term.

The results highlight how demanding the assessment requirements are of teachers in SCL classrooms. On average they use 11 different types of assessment that they tend to develop on their own or with peers and revise on a regular basis, before and during the academic term. 


\section{Grading and Feedback-Giving Practices}

Assessment in service of learning does not end when feedback and/or grades are returned to the student. Rather, the information gained from the assessment must lead to actions that ultimately support student improvement.

\section{SCL Teacher Grading Practices}

Grades provide students with an indication on how well they are doing compared to a standard or to other students. Though grades are sometimes criticized as being too reductive for students to benefit from and for promoting competition among students, only a small minority of our respondents avoid grades entirely. The majority of respondents typically give numeric or letter end-of-term grades (103 responses, $57.2 \%)$ and for assignments given during the term $(95,52.8 \%)$. A second large group gives students grades on an ordinal scale or a pass/fail indication at the end of the term $(65,36.1 \%)$ and for in-term assignments $(69,38.4 \%)$. Only a small portion of the respondents do not assign any end-of-term grades $(12,6.7 \%)$ or in-term grades $(16,8.9 \%)$.

In determining how to grade student assignments, teachers often use grading instruments. In our sample, a large portion reported to typically using a grading rubric (110 responses, $61.1 \%)$, followed by an answer key $(29$, $16.1 \%)$ and scoring guide $(20,11.1 \%)$. $11(6.1 \%)$ respondents do not use any grading instrument which is in line with the number of respondents that

Figure 8: Grading Instrument

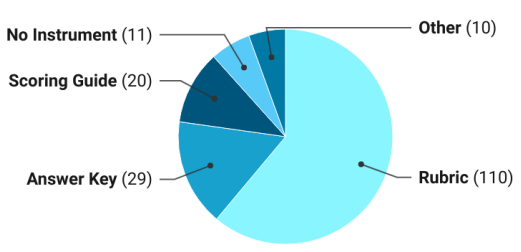
do not assign grades. 10 respondents chose the 'other' option and for the most part added that they use either a combination of two grading instruments (e.g., scoring guide and rubric) or that the grading instrument varies based on the assignment. 


\section{SCL Teacher Feedback-Giving Practices}

Written or verbal feedback is commonly given to students in addition to grades. Feedback is seen as crucial in contextualizing grades, evoking students' reflection on their learning progress and learning processes, and in providing guidance and emotional support. About half of the respondents in this sample provide their students with feedback for every assignment (88 responses, $48.9 \%$ ) while others provide students with feedback only on major assignments such as end-of-term projects $(50,27.8 \%)$ or only on formative assessments given during the term (31, 17.2\%). 11 (6.1\%) respondents report not providing students with any feedback other than grades or tick-marks.

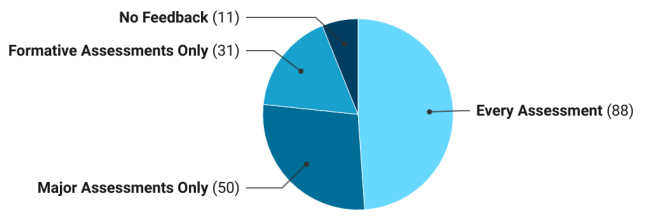

(a) Feedback Frequency

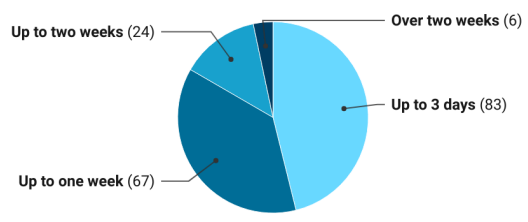

(b) Feedback Immediacy

Figure 9: Feedback Frequency and Immediacy

The time span between performing a task and receiving feedback for it can influence the effectiveness of the feedback. It is therefore usually recommended to give 'timely' feedback to students. The definition of timely may vary based on the task and the student. Teachers in this sample tend to provide feedback very soon after assignments are submitted, with 83 respondents (46.1\%) typically providing feedback within 3 days, and 67 more $(37.2 \%)$ within a week, leaving 30 respondents $(16.7 \%)$ who typically take more than a week to provide feedback to their students. 


\section{Teacher Feedback Orientation Spectrum}

A goal of this survey was to develop two new instruments. The first instrument, called the Teacher Feedback Orientation Spectrum (TFOS) aims to measure the type of feedback given by teachers to their students. It is important to stress that the results presented here are preliminary and that the instrument is in need of in-depth analysis before it can be viewed as reliable and valid. However, since it was included in the survey, we provide early readers with information about the proposed structure of the instrument and some initial results.

The instrument assumes a hierarchical structure with a general feedback-giving trait that comprises three main feedback types, differentiating between Formative, Summative, and Affective forms of feedback, each one further divided into sub-categories as described in Table 1.

Table 1: Categories and Sub-Categories of the TFOS

\begin{tabular}{|c|c|c|c|}
\hline Category & Sub-Category & Description & Example Item \\
\hline \multirow[t]{3}{*}{ Formative } & Metacognitive & $\begin{array}{l}\text { Encourages students to think about } \\
\text { their learning process rather than outcomes }\end{array}$ & $\begin{array}{l}\text { I avoid encouraging students } \\
\text { to reflect on their learning } \\
\text { processes (reverse-scored) }\end{array}$ \\
\hline & Directive & $\begin{array}{l}\text { Provides students with explicit instruction } \\
\text { on how to improve their work }\end{array}$ & $\begin{array}{l}\text { My feedback is specific } \\
\text { and tells students what to } \\
\text { change their work }\end{array}$ \\
\hline & Facilitative & $\begin{array}{l}\text { Provide students with tools and } \\
\text { guidance to think for themselves } \\
\text { what can be improved in their work }\end{array}$ & $\begin{array}{l}\text { In feedback, I describe student } \\
\text { work to stimulate discussion } \\
\text { about how it could improve }\end{array}$ \\
\hline \multirow[t]{2}{*}{ Summative } & Evaluative & $\begin{array}{l}\text { Provides students with information on how } \\
\text { they meet the requirements of the assignment } \\
\text { (criterion-referenced feedback) }\end{array}$ & $\begin{array}{l}\text { Written feedback I give to } \\
\text { students lets them know whether } \\
\text { I think they did a good job }\end{array}$ \\
\hline & Comparative & $\begin{array}{l}\text { Provides students with information } \\
\text { on how they measure up to their peers } \\
\text { (norm-referenced feedback) }\end{array}$ & $\begin{array}{l}\text { The feedback I give students } \\
\text { lets them know where they stand } \\
\text { compared to their peers }\end{array}$ \\
\hline \multirow[t]{2}{*}{ Affective } & Motivational & $\begin{array}{l}\text { Uses feedback to increase } \\
\text { student motivation to learn }\end{array}$ & $\begin{array}{l}\text { My feedback is full of } \\
\text { encouraging and positive comments }\end{array}$ \\
\hline & $\begin{array}{l}\text { Self-Esteem } \\
\text { Oriented }\end{array}$ & $\begin{array}{l}\text { Uses feedback to improve } \\
\text { students' self-esteem }\end{array}$ & $\begin{array}{l}\text { In feedback, I try to make } \\
\text { students feel good about } \\
\text { themselves }\end{array}$ \\
\hline
\end{tabular}

The survey results tell us that on average SCL teachers regularly give their students a lot of affective and formative feedback, with the addition of evaluative feedback. Comparative feedback, which is often seen as potentially detrimental to students, is typically avoided, scoring significantly lower than other feedback categories. It is also worth noting that SCL teachers seem to see feedback as an opportunity to support student motivation and self-image. It has long been a contentious issue whether assessments should focus on aspects of student work like effort or whether feedback should include praise or comments relating to students' self-image. However, at least in this sample, it seems that this issue is not of concern to respondents and they mainly see the benefits in giving their students affective feedback even more than formative types of feedback or evaluative feedback. 
Figure 10: TFOS Mean Scores

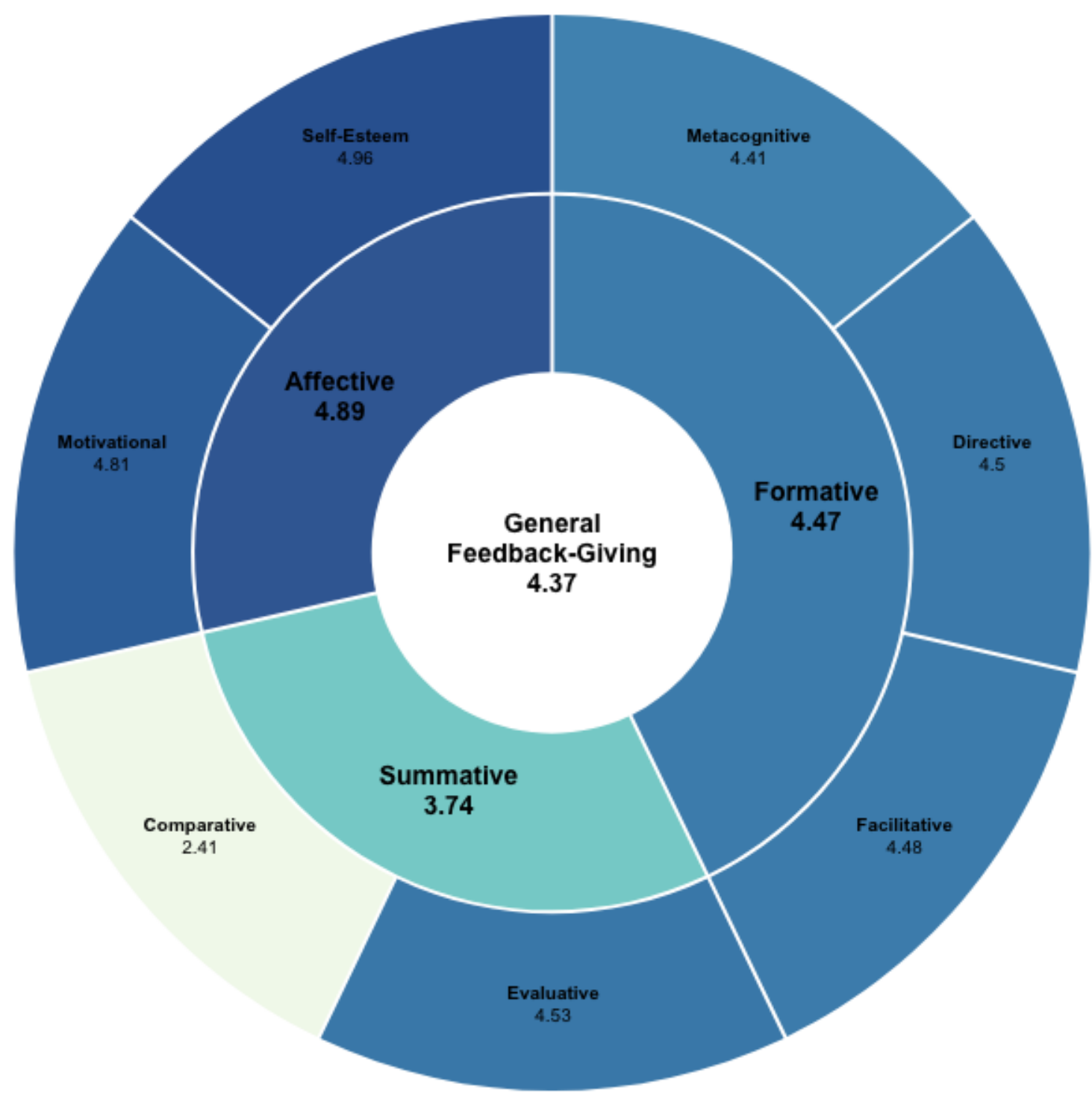




\section{Feedback Benefits and Costs (FBC)}

The second instrument that was included in this survey, called 'Feedback Benefits and Costs', aims to measure the benefits and costs teachers associate with giving feedback to their students. The instrument suggests benefits and costs associated with feedback-giving as described in Table 2 .

To be clear, costs and benefits are seen as two scales here rather than two sides of the same scale. A teacher may perceive certain practices as strongly beneficial and, hence, justifying their costs. But this does not mean that the teacher must perceive the same practices as low in effort or other potential cost. Conversely, a teacher may perceive feedback to be low benefit and also low cost (perhaps low effort follows from the perception of low value).

Table 2: Categories and Sub-Categories of the FBC

\begin{tabular}{llll} 
Category & Sub-Category & Description & Example Item \\
\hline \multirow{3}{*}{ Benefits } & Achievement & $\begin{array}{l}\text { A belief that feedback it } \\
\text { central in the learning process }\end{array}$ & $\begin{array}{l}\text { Giving students feedback is } \\
\text { important because it helps them learn }\end{array}$ \\
\cline { 2 - 4 } & Self-Regulation & $\begin{array}{l}\text { A belief that quality feedback provides } \\
\text { students with tools to evaluate their } \\
\text { own work }\end{array}$ & $\begin{array}{l}\text { Good feedback should remind } \\
\text { each student to self-assess his } \\
\text { or her own work }\end{array}$ \\
\cline { 2 - 4 } & $\begin{array}{l}\text { Teacher-Student } \\
\text { Relationships }\end{array}$ & $\begin{array}{l}\text { A belief that feedback is an important part } \\
\text { between teachers and their students }\end{array}$ & Giving feedback to students shows \\
& $\begin{array}{l}\text { Irrelevance } \\
\text { (Reverse-Scored) }\end{array}$ & $\begin{array}{l}\text { A belief that the benefits of feedback are } \\
\text { diminished by students' disinterest in it }\end{array}$ & $\begin{array}{l}\text { Feedback is pointless because students } \\
\text { ignore my comments and directions }\end{array}$ \\
\hline \multirow{3}{*}{ Costs } & $\begin{array}{l}\text { Resources } \\
\text { Consumption }\end{array}$ & $\begin{array}{l}\text { A belief that giving students quality feedback is } \\
\text { hard and time-consuming }\end{array}$ & $\begin{array}{l}\text { Giving feedback to students requires } \\
\text { a lot of mental effort }\end{array}$ \\
\cline { 2 - 4 } & $\begin{array}{l}\text { Negative } \\
\text { Affect }\end{array}$ & $\begin{array}{l}\text { A belief that giving students feedback may have } \\
\text { an adverse effect on their self-esteem or } \\
\text { motivation to learn }\end{array}$ & $\begin{array}{l}\text { The feedback I give to students makes } \\
\text { them feel they are being criticized }\end{array}$
\end{tabular}

On average, the teachers in this sample perceive feedback-giving as very beneficial and associate low to medium costs in giving it to students. Though all scores in the benefits sub-categories are on the high end, it seems that teachers in this sample feel that feedback is perhaps more beneficial in supporting student learning and building teacher-student relationships than promoting self-regulation in students. It is also noteworthy that the high irrelevance score indicates that students' disinterest in feedback is not of concern for our teachers. 
Figure 11: FB\&C Mean Scores

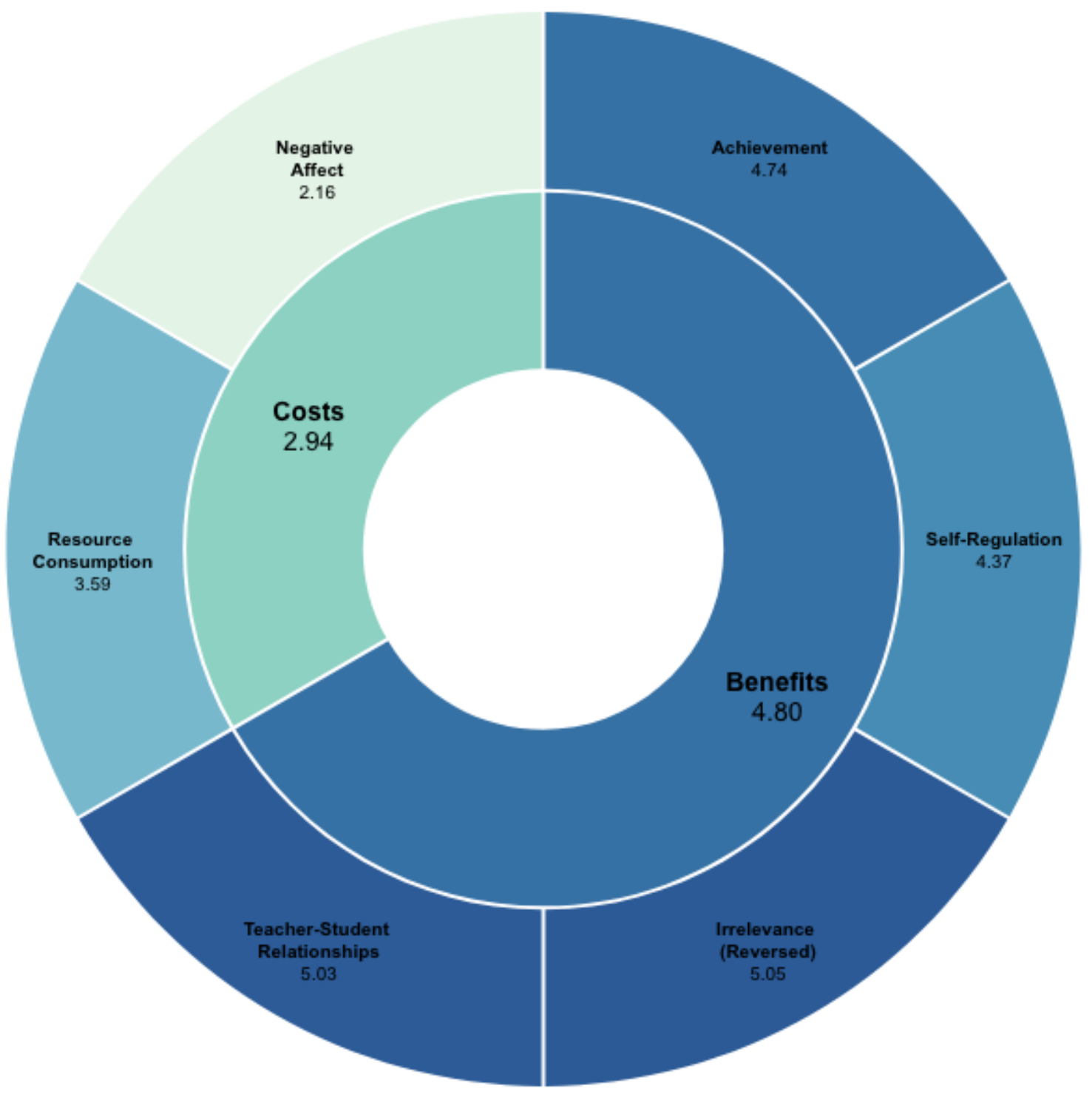

In terms of costs, resource consumption is more of a concern than causing negative emotions in students. Perhaps since teachers in this sample tend to have extensive teaching experience they feel confident in their ability to provide students feedback without causing negative emotions. The cost in terms of time and energy is seen as greater. While experience can ameliorate the negative emotional and motivational effects feedback can create, it cannot erase the time and energy that quality feedback requires. It does, however, seem that teachers in this sample evaluate the benefits as greater than the costs. This is consistent with the results in the feedback practices section. 


\section{Conclusion and Next Steps}

This research brief offers a preliminary review of the survey results collected from a sample of 180 SCL classroom teachers in the US. What we see from the results so far is that the task of assessing and supporting students through feedback in SCL classrooms is demanding and requires skill and dedication. In our sample we encountered teachers with extensive education and experience who report to using a wide range of assessment types. Each type is used multiple times during a given academic term and is most likely developed by the teacher, with or without the help of their colleagues. The teachers in this sample value the benefits of giving feedback and are willing to pay the time and energy costs needed to provide it to their students on a regular basis. The feedback is used by SCL teachers to promote several goals ranging from improving learning, self-regulation, providing motivational and emotional support, and letting students know where they stand compared to standards (but not compared to their peers).

While we see these initial results as informative and relevant for supporting SCL teachers in their assessment and feedback-giving practices, there are additional steps that need to be carried out. First, we intend to analyze each instrument for reliability and validity. If these instruments meet quality thresholds, they may be used to assess (or self-assess) where teachers stand in terms of the types of feedback they give their students and their perception of the benefits and costs associate with the process of giving feedback. For example, these instruments can be used as part of a preevaluation going into a professional development or similar setting to identify the needs of specific teachers. Second, since there are expected to be meaningful differences in practices and beliefs among SCL teachers, there is value in comparing subgroups, whether by pedagogical approach, teaching experience, or assessment training.

We wish to thank all the teachers who participated in this survey, whether by answering it or by sharing it with their peers. (If you are one of those teachers reading this, we hope you found this report to be insightful and respectful). Special thanks to our friends at STEMteachersNYC, MakerEd, and Fablearn who helped us try (again and again) to reach a wide network of teachers.

\section{References}

Brown, G. T., Harris, L. R., \& Harnett, J. (2012). Teacher beliefs about feedback within an assessment for learning environment: Endorsement of improved learning over student wellbeing. Teaching and Teacher Education, 28(7), 968-978.

Pat-El, R. J., Tillema, H., Segers, M., \& Vedder, P. (2013). Validation of assessment for learning questionnaires for teachers and students. British Journal of Educational Psychology, 83(1), 98-113. 